\title{
Ampullary Flat Intraepithelial Neoplasia, High Grade
}

National Cancer Institute

\section{Source}

National Cancer Institute. Ampullary Flat Intraepithelial Neoplasia, High Grade. NCI

Thesaurus. Code C95918.

A non-polypoid, preinvasive neoplasm that arises from the ampulla of Vater. It is

characterized by the presence of high grade dysplasia. 